\title{
Assortative interactions and leadership in a free-ranging population of juvenile lemon shark Negaprion brevirostris
}

\author{
Tristan L. Guttridge ${ }^{1, *}$, Samuel H. Gruber ${ }^{2,3}$, Joseph D. DiBattista ${ }^{4}$, \\ Kevin A. Feldheim ${ }^{5}$, Darren P. Croft ${ }^{6}$, Stefan Krause ${ }^{7}$, Jens Krause ${ }^{8}$
}

${ }^{1}$ Institute for Integrative and Comparative Biology, University of Leeds, L.C. Miall Building, University of Leeds, Leeds LS2 9JT, UK

${ }^{2}$ Bimini Biological Field Station, 15 Elizabeth Drive, South Bimini, Bahamas, and ${ }^{3}$ Division of Marine Biology and Fisheries, Rosenstiel School of Marine and Atmospheric Science, 4600 Rickenbacker Causeway, Miami, Florida 33149, USA

${ }^{4}$ Hawaii Institute of Marine Biology, University of Hawaii at Manao, PO Box 1346 Coconut Island, Kaneohe, Hawaii 96744, USA

${ }^{5}$ Field Museum, Pritzker Laboratory for Molecular Systematics and Evolution, 1400 South Lake Shore Drive, Chicago, Illinois 60605, USA

${ }^{6}$ Centre for Research in Animal Behaviour, School of Psychology, University of Exeter, Exeter EX4 4QJ, UK

${ }^{7}$ Department of Electrical Engineering and Computer Science, Lübeck University of Applied Sciences, 23562 Lübeck, Germany

${ }^{8}$ Leibniz-Institute of Freshwater Ecology and Inland Fisheries, Department of Biology and Ecology of Fishes, Berlin 12587, Germany

\begin{abstract}
For marine predators there is a paucity of studies on social behaviour, and even fewer studies have quantified interactions between individuals. In the present study, we looked at the social structure and leadership of free-ranging juvenile lemon shark Negaprion brevirostris in a known aggregation site, Bimini, the Bahamas. Observations of these sharks were made from towers placed in a mangrove inlet, where clear, shallow, protected waters made it possible to record group compositions of externally colour-code tagged wild juvenile lemon sharks. Thirty-eight different individual sharks were observed to use the area over a 2 yr period. Results show repeated social interactions suggestive of active partner preference. In addition, we found that group structure was mostly explained by body length, and possibly by preference for relatives but not by sex. Finally, we observed that some sharks led more groups than others and that those lead individuals were usually larger than those following them. This study quantifies the social structure of a free-ranging shark population and provides novel insights into the social behaviour of juvenile sharks.
\end{abstract}

KEY WORDS: Lemon shark · Group living · Social organisation · Social behaviour · Size assortment · Relatedness $\cdot$ Randomisations

Resale or republication not permitted without written consent of the publisher

\section{INTRODUCTION}

Social behaviour implies a number of individuals living and interacting with each other (Krause \& Ruxton 2002). Studying such interactions helps us to understand the mechanisms as well as the causes and consequences of sociality (Croft et al. 2008, Whitehead
2008). Many wild-animal groups are known to display non-random patterns of social structure and are often assorted by phenotypic characteristics, such as body size, sex, relatedness, colour and parasite load (Krause \& Ruxton 2002, Ward \& Hart 2003). This assortment is thought to confer advantages associated with foraging and anti-predatory behaviour (Krause \& Ruxton 2002). 
Sharks are regularly observed to form groups or loose aggregations (Klimley 1983, Economakis \& Lobel 1998, Dudgeon et al. 2008, Kessel 2010); however, the social organisation and structure of these groups has received considerably less attention than in other marine animals, such as teleost fishes and cetaceans (Croft et al. 2003, Whitehead 2008). Patterns of association for sharks are difficult to reveal due to the concealing nature of their environment, making social interactions difficult to observe, let alone quantify (Heupel \& Simpfendorfer 2005). Quantitative information regarding shark social interactions has only been collected in a handful of studies, predominantly on captive sharks (Allee \& Dickinson 1954, Myrberg \& Gruber 1974, Klimley 1983, Jacoby et al. 2010). These studies revealed that social interactions between individuals occur and their frequency and duration seem to be determined by individual attributes, such as size or sex, with larger individuals occupying central positions in schools and lead positions in follow formations (Myrberg \& Gruber 1974, Klimley 1983). Recently, Guttridge et al. (2009a) experimented with captive subjects under semi-controlled conditions to investigate the social preferences of juvenile lemon shark Negaprion brevirostris. These sharks demonstrated an active preference to be social versus solitary even when resources such as access to food were controlled for. Furthermore, juvenile lemon sharks preferred to associate with conspecifics as well as groups consisting of size-matched individuals. These findings indicate that social preferences might well play an important role in the formation and composition of free-ranging groups of juvenile sharks. Interestingly, lemon sharks from all life stages have been documented to form groups (Gruber et al. 1988, Reyier et al. 2008, Garla et al. 2009). Large numbers of adult lemon sharks come together over the winter months in Florida, USA, resting in close proximity and performing social behaviours, such as 'follow head to tail' (Kessel 2010).

In recent years, researchers have used social network analysis (SNA) to assess social structure across a diversity of taxa, including insects (Fewell 2003), cetaceans (Lusseau 2003), teleost fishes (Croft et al. 2004) and reptiles (Godfrey et al. 2009, see Krause et al. 2007 and Croft et al. 2008 for reviews). A network is simply a graph consisting of nodes connected by edges. In the context of a social network, each node normally represents an individual animal and each edge represents some measured social interaction or association value (Croft et al. 2008). This graph provides visual representation of a population's social structure and a quantitative framework from which we can characterise social structure both at the level of the individual and population (Krause et al. 2007). More recently, re- searchers have developed null models in network theory that typically consist of randomisations or socalled Monte Carlo simulations (Krause et al. 2008), where an empirical data set is compared to itself using a series of randomisations. With the help of this technique it is possible to determine whether persistent pair-wise interactions are present in the network (Croft et al. 2008) and to search for associative patterns based on body length, relatedness and sex (Lusseau 2003, Croft et al. 2005).

The aim of the present study was to carry out a detailed analysis of the social structure of a population of free-ranging juvenile sharks. Using randomisation techniques we searched for associative patterns in groups of wild juvenile lemon shark Negaprion brevirostris in Bimini, the Bahamas. Based on the findings of Guttridge et al. (2009a) cited above, we predicted that free-ranging juvenile lemon sharks would display repeated social interactions made up of size-matched conspecifics.

Sex and size segregation are common in the animal kingdom (Ruckstuhl \& Neuhaus 2005: vertebrates) and are apparently widespread in sharks (Gruber \& Myrberg 1977, Wearmouth \& Sims 2008, Mucientes et al. 2009). Such segregation is often determined through fishery-capture records and through the use of ultrasonic telemetry. For elasmobranchs, a number of hypotheses have been put forward to account for this segregation, including predation risk, forage selection, activity budget, thermal niche-fecundity and social factors (Klimley 1987, Economakis \& Lobel 1998, Wearmouth \& Sims 2008). Previous behavioural studies at Bimini have demonstrated that juvenile lemon sharks do not show sex differences in habitat or prey selection (Gruber et al. 1988, Morrissey \& Gruber 1993, Newman 2003, Franks 2007). Accordingly, we expected that juvenile lemon shark groups would not assort by sex.

Kin-structured social groups have previously been documented for a range of taxa (Parsons et al. 2003, Fraser et al. 2005). However, as far as we know, the question of whether sharks avoid or preferentially associate with kin has been completely unexplored. Reproductively active female lemon sharks usually return biennially to specific nursery grounds to give birth (mean litter size $=7$, range $=4$ to 18 ) (Feldheim et al. 2002). After parturition, juvenile lemon sharks display high site fidelity in their first few years of life (Morrissey \& Gruber 1993, Franks 2007), suggesting that social encounters between related individuals are highly probable. Finally, in accordance with previous studies on dominance hierarchies in captive sharks, we predicted that larger juvenile lemon sharks would lead groups more often than smaller conspecifics (Myrberg \& Gruber 1974, Brown 2004). 


\section{MATERIALS AND METHODS}

Study site. The present study was conducted at Bimini, the Bahamas $\left(25^{\circ} 44^{\prime} \mathrm{N}, 79^{\circ} 16^{\prime} \mathrm{W}\right)$, a small chain of islands approximately $85 \mathrm{~km}$ east of Miami, Florida, USA. Research focused on the southeast coast of East Bimini in an area known as Bone Fish Hole (Fig. 1a). This location is heavily fringed with red mangrove Rhizophora mangle and provides sheltered, shallow, warm water that is ideal primary and secondary nursery habitat for young lemon sharks (Gruber et al. 1988). At high tide, water flushes the area and rushes deep into the mangroves enabling access to small tidally dependent mangrove lagoons and channels. We have incidentally observed one of these areas, known as Aya's Spot $\left(25^{\circ} 43.8^{\prime} \mathrm{N}\right.$, $79^{\circ} 14.7^{\prime} \mathrm{W}$; Fig. 1b) for several years and recognized it as an aggregation site for juvenile lemon sharks with as many as 25 individuals using the site at high tide (water depth: 0.2 to $0.9 \mathrm{~m}$ ). When systematically observed, we found that they spent their time performing group behaviours, such as follow, circle or parallel (Myrberg \& Gruber 1974). When not in groups, solitary sharks were observed to patrol the area, neither feeding nor interacting agonistically with each other (Guttridge 2009).

Shark capture and individual recognition. We captured 58 juvenile lemon sharks $(\mathrm{N}=25$ females and $\mathrm{N}=$ 33 males; mean total length $\pm \mathrm{SD}=79 \pm 12.3 \mathrm{~cm}$ ) at Aya's Spot, over the period from May 2006 to May 2008. Of these sharks, 38 were observed to re-use the area regularly throughout this $2 \mathrm{yr}$ period (Guttridge 2009). Sharks were captured or recaptured every 3 to 4 mo using a seine net at high tide that was stretched across a channel blocking the exit of Aya's Spot (Fig. 1b). When sharks exited they were trapped in the netting, immediately removed and processed (described elsewhere in detail, DiBattista et al. 2008). Briefly, all sharks were checked for a passive integrated transponder (PIT) tag, measured (pre-caudal, fork and total length), weighed and sexed, and a small piece of fin was collected for genetic analysis. Furthermore, to provide external identification, each shark was marked with a unique colour-coded tag (T-bar type, Floy Tag Manufacturing) through the first or second dorsal fin. The colours and placement of these tags were changed each time sharks were captured, to minimise the effect that these had on shark associations.
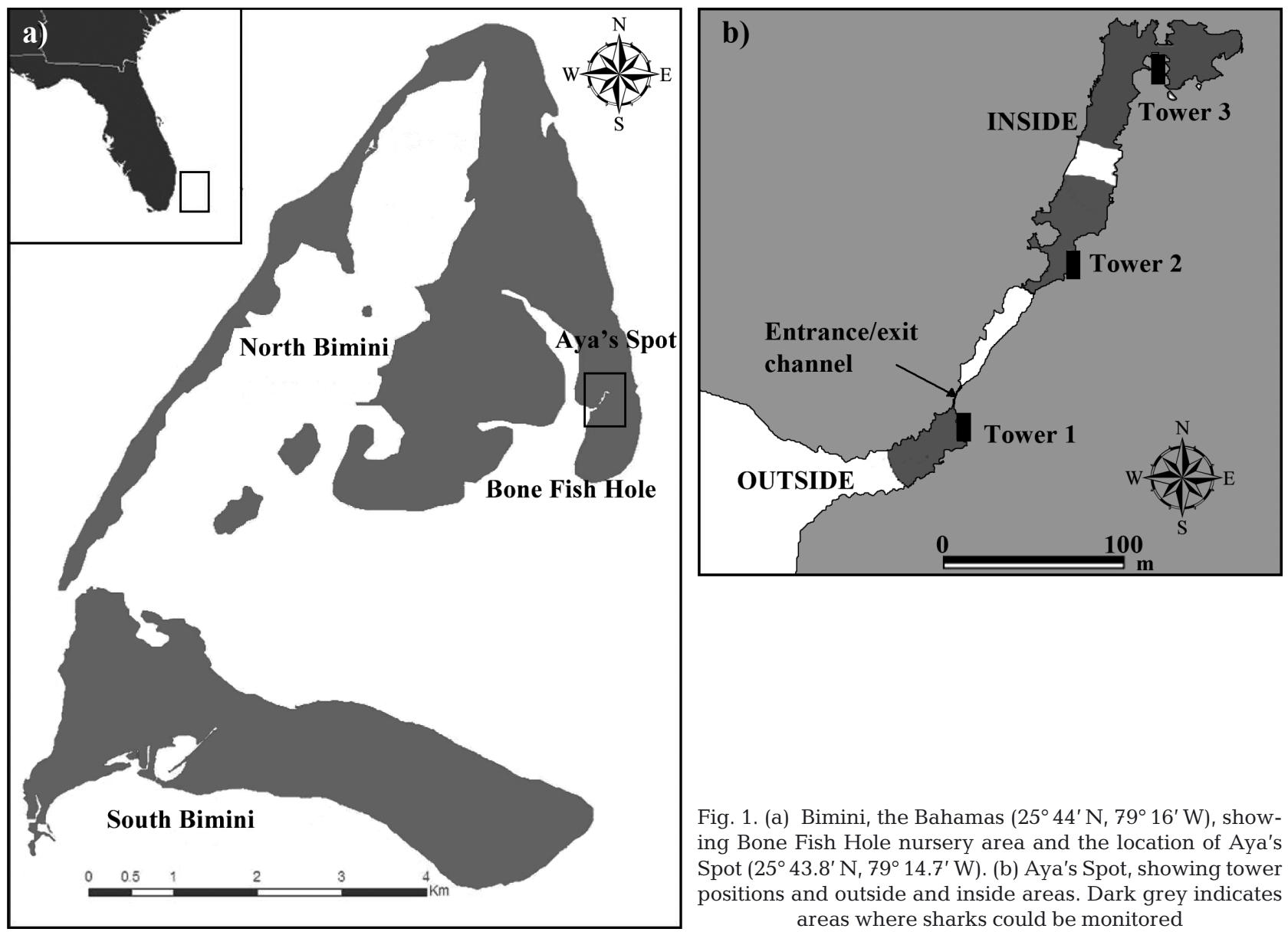

Fig. 1. (a) Bimini, the Bahamas $\left(25^{\circ} 44^{\prime} \mathrm{N}, 79^{\circ} 16^{\prime} \mathrm{W}\right)$, showing Bone Fish Hole nursery area and the location of Aya's Spot ( $25^{\circ} 43.8^{\prime}$ N, 79 $14.7^{\prime}$ W). (b) Aya's Spot, showing tower positions and outside and inside areas. Dark grey indicates areas where sharks could be monitored 
Observations and defining social interactions. Observations were conducted simultaneously from 3 towers positioned in locations that provided almost complete coverage of Aya's Spot (Fig. 1b). A total of 83 observation days were conducted between May 2006 and May 2008 and were selected based on the following criteria: (1) high tide; and (2) low wind speed (i.e. $<20 \mathrm{~km} \mathrm{~h}^{-1}$ ). Observing with binoculars under these conditions ensured that water surface and light levels optimized our ability to identify individual sharks within $40 \mathrm{~m}$ of the towers (Fig. 1b). In addition, preliminary visual observations during low tide and data from an acoustic telemetry study on movements indicated that sharks apparently did not use the area over the low tide and were detected at a range of wind speeds (Guttridge 2009).

The following information was collected during observation days from sharks within identifiable range of the towers:

(1) Shark presence - time of observation and shark identity confirmed through visual identification of colour-code tags.

(2) Scan sampling (every $2 \mathrm{~min}$ ) - time, shark identity and social behaviour (described in Table 1) of sharks.

During each 2 min, scan information was recorded on (1) the identities and social behaviour of sharks within all observed groups, if a 'follow formation' was observed the lead individual identity was also noted; and (2) the identities of any solitary sharks. Following Pitcher \& Parrish (1993), we defined a 'social group' as 2 or more sharks swimming in an apparently coordinated manner within $\sim 3$ to 4 body lengths of one another for a period of $1 \mathrm{~min}$ or more.

Table 1. Negaprion brevirostris. An ethogram of juvenile lemon shark social behaviours, based on observations and Myrberg \& Gruber (1974). All interactions were only recorded if they lasted for $1 \mathrm{~min}$ or longer

\begin{tabular}{|c|c|}
\hline Behavioural states & Definition of behaviour \\
\hline Following & $\begin{array}{l}\text { Two or more sharks observed within } \\
4 \text { body lengths of each other. Trail- } \\
\text { ing sharks mimic the directional } \\
\text { changes of the lead individual. }\end{array}$ \\
\hline Paralleling & $\begin{array}{l}\text { Two or more sharks observed within } \\
1 \text { body length of each other. Sharks } \\
\text { must be parallel with the pectoral } \\
\text { fins in line. Both sharks exhibit the } \\
\text { same directional changes in swim- } \\
\text { ming behaviour. }\end{array}$ \\
\hline Circling & $\begin{array}{l}\text { Two or more sharks swimming in a } \\
\text { circle, head to tail. }\end{array}$ \\
\hline Milling & $\begin{array}{l}\text { Two or more sharks swimming } \\
\text { within } 4 \text { body lengths but not ex- } \\
\text { hibiting any coordinated directional } \\
\text { changes. }\end{array}$ \\
\hline
\end{tabular}

Observation days, where groups of sharks were recorded ( $\mathrm{N}=60)$, were split into 4 time periods: (1) May to December 2006 (30 d); (2) January to May 2007 (9 d); (3) May to December 2007 (16 d); and (4) January to May 2008 (5 d). This was to ensure that neonate sharks born in April and May could be included in the analysis post June 2007 and that shark growth was not a confounding factor on the observed patterns (as shark body length was updated for each time period).

Genetic methods. DNA was extracted from fin clips of all individuals caught at the study site and genotyped at 11 species-specific microsatellite loci as previously described (Feldheim et al. 2002, DiBattista et al. 2008). Sharks were classified as siblings or non-siblings using Kinship 1.3 (Goodnight \& Queller 1999). Kinship calculates Queller and Goodnight's r (Queller \& Goodnight 1989) between pairs of individuals in a population. This is the ratio $(r)$ of a primary hypothesis (in our case sibling relationship between individuals) to the null hypothesis (in our case no relatedness between individuals). Significance of the ratio is then determined by simulation. Three significance levels, $\mathrm{p}=0.05, \mathrm{p}=0.01$, and $\mathrm{p}=0.001$, are generated by the simulation for each pair of individuals (Goodnight \& Queller 1999). We used kinship significance levels of $p=0.01$ and $p=0.001$ to conservatively determine sibling relationships.

Randomisation methods. Social networks were constructed and analysed from information on group composition for all 4 time periods. We decided to focus on time periods (1) and (3) because they had the largest number of observation days, but patterns were actually similar for all 4 time periods (see Appendix 2). A total of 1836 groups were recorded on 46 observation days (30 d [1] and $16 \mathrm{~d}$ [3]), with a maximum of 126 groups and a minimum of 4 (mean $\pm \mathrm{SD}=40 \pm 30$ ) observed on a given day. Group size ranged from 2 to 11 individuals with $\sim 60 \%$ of groups being pairs of sharks, which was true for all 4 time periods of this study (Fig. 2a). Sharks interacted in groups for $<2 \mathrm{~min}$ to a maximum of $46 \mathrm{~min}$. The majority of groups lasted $<2 \min (80 \%)$ with $<3 \%$ of groups lasting longer than 6 min for all time periods (Fig. 2b). The duration of grouping was important in determining when 2 groups could be considered independent of each other. Using this information, we conducted the analysis such that group membership was randomised between groups that were 10 and 60 min apart on each day. We used 2 different time limits to test whether results were consistent even when using a more conservative criterion for selecting independent groups.

Data analysis. Social structure: To assess whether the shark groups were of a non-random structure and exhibited assortment based on size, sex and relatedness, a series of randomisation tests were carried out. 

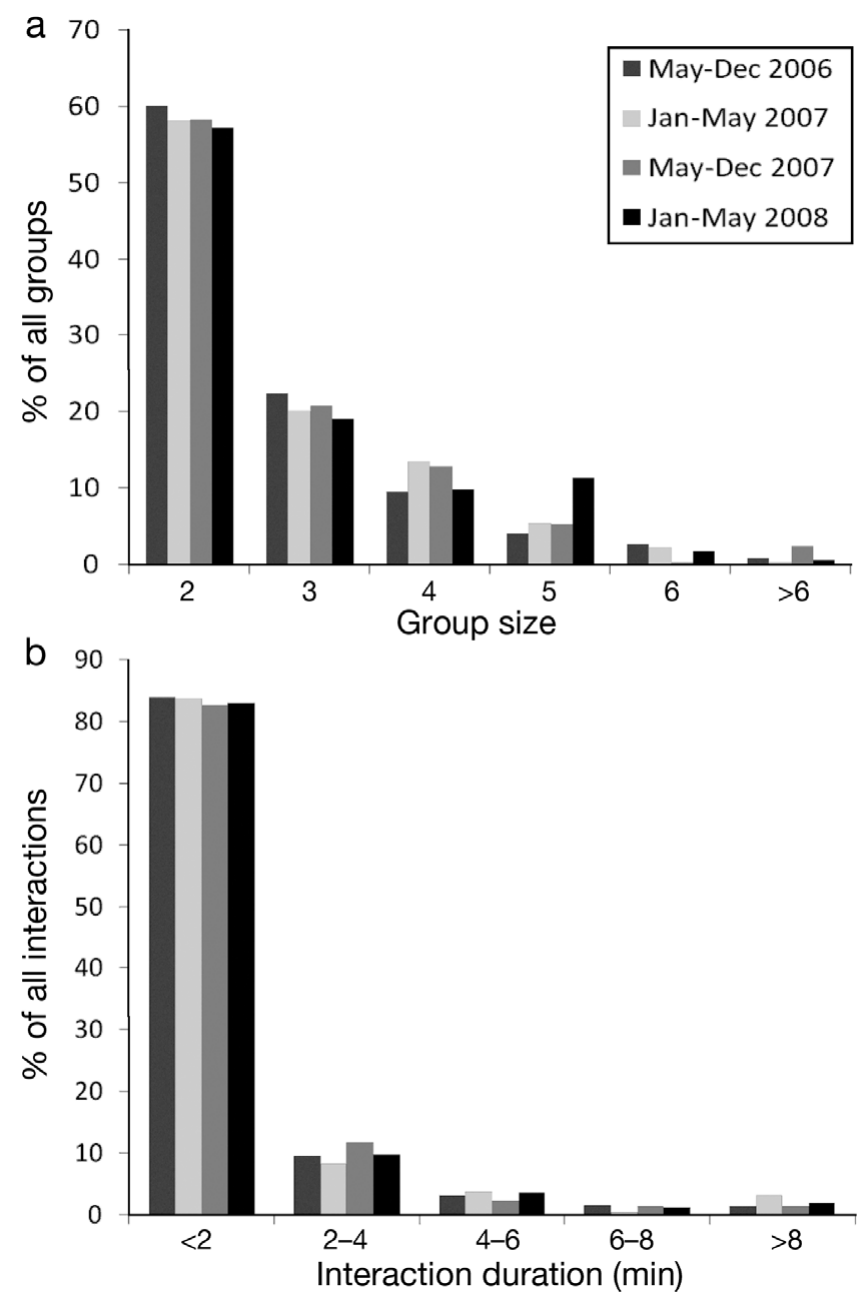

Fig. 2. Negaprion brevirostris. (a) Percentage of group sizes for all groups and all 4 time periods. (b) Durations of interactions for groups of juvenile lemon sharks, for all time periods

To test for non-randomness of the social structure, association strength square sum (ASSS) was used (Croft et al. 2004). This statistic measured the number of times a pair of individuals was seen in the same group in each time period. The sum of squares of the association strength values was then computed for all possible pairs in the matrix. For size assortment, we calculated each group's standard deviation and then summed them all. For sex assortment, we counted the number of males and females in each group and then computed the sum of the maximum numbers. For the relatedness analysis, we counted the number of related (full and half siblings) pairs in each group and then computed the sum of the maximum numbers. All 4 test statistics were then calculated $10^{8}-1$ times using a Markov Chain Monte Carlo (MCMC) randomisation approach (see Krause et al. 2008 for details) providing expected frequency distributions for each test statistic. $\mathrm{p}$-values were obtained by comparing the test statistic expected values with the observed ones. For the above randomisations, groups of all sizes were selected (range 2 to 11 ); however, $\sim 60 \%$ of all groups were pairs. Further randomisations were carried out on group sizes of $2,>2$ and $>3$ to investigate whether assortative patterns continued to persist in larger group sizes (see Appendix 1).

Leadership: Further test statistics were required for the leadership analysis because we wanted to investigate whether certain sharks led groups more often than others, regardless of size. We thus counted the frequency that each individual was leading a group and then computed the sum of the squares of these frequencies (leadership frequency square sum, LFSS). If some individuals led more often, then high LFSS values would be produced. Next, we investigated the relationship between body size and leadership in groups. For this, we counted the number of individuals in each group that were smaller than the group leader and summed the results (SLS). If larger sharks led more groups, then we expected to obtain high SLS values. To generate expected values for LFSS and SLS test statistics we used a Monte Carlo approach that computed $10^{6}-1$ randomisations. p-values were obtained as described above.

\section{RESULTS}

\section{Observation information}

Groups of sharks were recorded on 60 of the 83 observation days. The number of sharks using the area on a daily basis ranged from 0 to 14 tagged individuals (mean $\pm \mathrm{SD}=6 \pm 3$ ) and 0 to 4 untagged individuals (mean $\pm \mathrm{SD}=1 \pm 1$ ). Observation durations (defined as the total time between the first shark arriving and the last shark departing) peaked at $7.5 \mathrm{~h}$ on 1 observation day (mean $\pm \mathrm{SD}=2.9 \pm 2.1 \mathrm{~h}$ ). Individual lemon sharks were observed to use the area for varying temporal scales from 1 observation day to observations spanning $2.5 \mathrm{yr}($ mean $\pm \mathrm{SD}=6.2 \pm 7.2 \mathrm{mo})$.

\section{Social structure}

Juvenile lemon sharks formed repeated pair-wise interactions more often than expected (Table 2, Fig. 3a). Further analysis of group composition showed that juvenile lemon shark associations were significantly assorted by body length (Table 2, Fig. 3), but as expected not for sex (Table 2, Fig. 3). The relatedness analyses were less clear with significant assortment found in 2006 but not in 2007 or 2008 (Table 2, Appendix 2). Furthermore, different group sizes $(2,>2$ and $>3)$ were as- 
Table 2. Negaprion brevirostris. Summary results of association strength square sum (ASSS); size assortment based on the sum of standard deviations in all groups; sex assortment based on the sum of the maximum values of the number of males and females in all groups; and relatedness based on the number of related pairs of individuals in groups. Time period: period when observations were conducted; Time dist: time distance between selected groups within a day; No. groups: number of groups selected for each analysis; Observed score: test statistic score calculated for the selected observed groups; Min/max scores: minimum and maximum scores for each test statistic after completing $10^{8}-1$ randomisations. p-value was calculated by comparing the observed test statistic score to the expected

\begin{tabular}{|c|c|c|c|c|c|c|c|}
\hline Analysis & Time period & Time dist (min) & No. groups & Observed score & \multicolumn{2}{|c|}{ Min/max scores } & $\mathrm{p}$-value \\
\hline \multirow[t]{4}{*}{ ASSS } & May-Dec 06 & 10 & 337 & 15710 & 12390 & 15770 & 0.00005 \\
\hline & May-Dec 06 & 60 & 93 & 1240 & 1000 & 1410 & 0.03223 \\
\hline & May-Dec 07 & 10 & 249 & 18329 & 14991 & 18329 & 0.00002 \\
\hline & May-Dec 07 & 60 & 67 & 1168 & 844 & 1268 & 0.00006 \\
\hline \multirow[t]{4}{*}{ Size } & May-Dec 06 & 10 & 337 & 1809 & 1802 & 2385 & 0.00011 \\
\hline & May-Dec 06 & 60 & 93 & 489 & 488 & 663 & 0.00006 \\
\hline & May-Dec 07 & 10 & 249 & 1357 & 1357 & 1982 & 0.00003 \\
\hline & May-Dec 07 & 60 & 67 & 294 & 281 & 458 & 0.00017 \\
\hline \multirow[t]{4}{*}{ Sex } & May-Dec 06 & 10 & 337 & 591 & 585 & 644 & 0.9997 \\
\hline & May-Dec 06 & 60 & 93 & 159 & 152 & 186 & 0.9806 \\
\hline & May-Dec 07 & 10 & 249 & 510 & 490 & 528 & 0.3026 \\
\hline & May-Dec 07 & 60 & 67 & 116 & 113 & 131 & 0.9198 \\
\hline \multirow[t]{4}{*}{ Kin } & May-Dec 06 & 10 & 337 & 146 & 107 & 157 & 0.00402 \\
\hline & May-Dec 06 & 60 & 93 & 38 & 21 & 48 & 0.05350 \\
\hline & May-Dec 07 & 10 & 249 & 62 & 48 & 81 & 0.70755 \\
\hline & May-Dec 07 & 60 & 67 & 13 & 7 & 20 & 0.45019 \\
\hline
\end{tabular}

sessed separately for associative patterns because of the predominance of pairs and the results were similar (see Appendix 1).

\section{Leadership}

The randomisation tests showed that some individuals led groups significantly more often than others (Table 3). Further analysis revealed that the individual in the lead position was usually significantly larger than other members that were following it (Table 3). These findings were consistent for all 4 time periods.

\section{DISCUSSION}

The present study investigates and quantifies the social structure of a population of free-ranging, juvenile sharks. We found that groups of juvenile lemon sharks display a non-random social structure with persistent pair-wise associations within these groups. We also found this pattern for all four 6 mo observation periods and for a range of group sizes, indicating that individuals even within larger groups associate with non-random members. Studies on other marine animals, such as teleost fishes and cetaceans, have revealed similar non-random structures in social networks of free-ranging populations (Lusseau 2003, Croft et al. 2005) and are often put into the context of cooperative behaviours (Croft et al. 2006). At present we are unable to determine whether the observed pair-wise associations are fully accounted for by preferences for similar-sized individuals and kin. However, this finding raises an important question: Are lemon sharks capable of some level of social recognition? For teleost fishes this phenomenon is well studied (Griffiths 2003) and recent evidence has indicated that social recognition is a complex subject with species and populations capable of different levels of recognition (Ward et al. 2009). As far as we are aware, this phenomenon has not been explored in sharks (Guttridge et al. 2009b) and warrants investigation in the context of behavioural processes, such as foraging, navigation and reproduction.

Assortative interactions based on body length were observed in our shark groups, with individuals being more likely to associate with conspecifics of a similar body length. Body-length assortment in groups is common among marine and freshwater teleost fishes (Peuhkuri et al. 1997, Svensson et al. 2000, Croft et al. 2005) and is known to confer anti-predatory and foraging advantages (Landeau \& Terborgh 1986, Krause 1994). At the study site, large lemon sharks (>2 m), known to prey on juveniles (Morrissey \& Gruber 1993), were observed on 2 occasions in front of Tower 1 . On detection, juveniles displayed strong flight responses, apparently seeking cover in the shallow back section of Aya's Spot (Guttridge 2009). Further to this, an acoustic study conducted in parallel identified that 

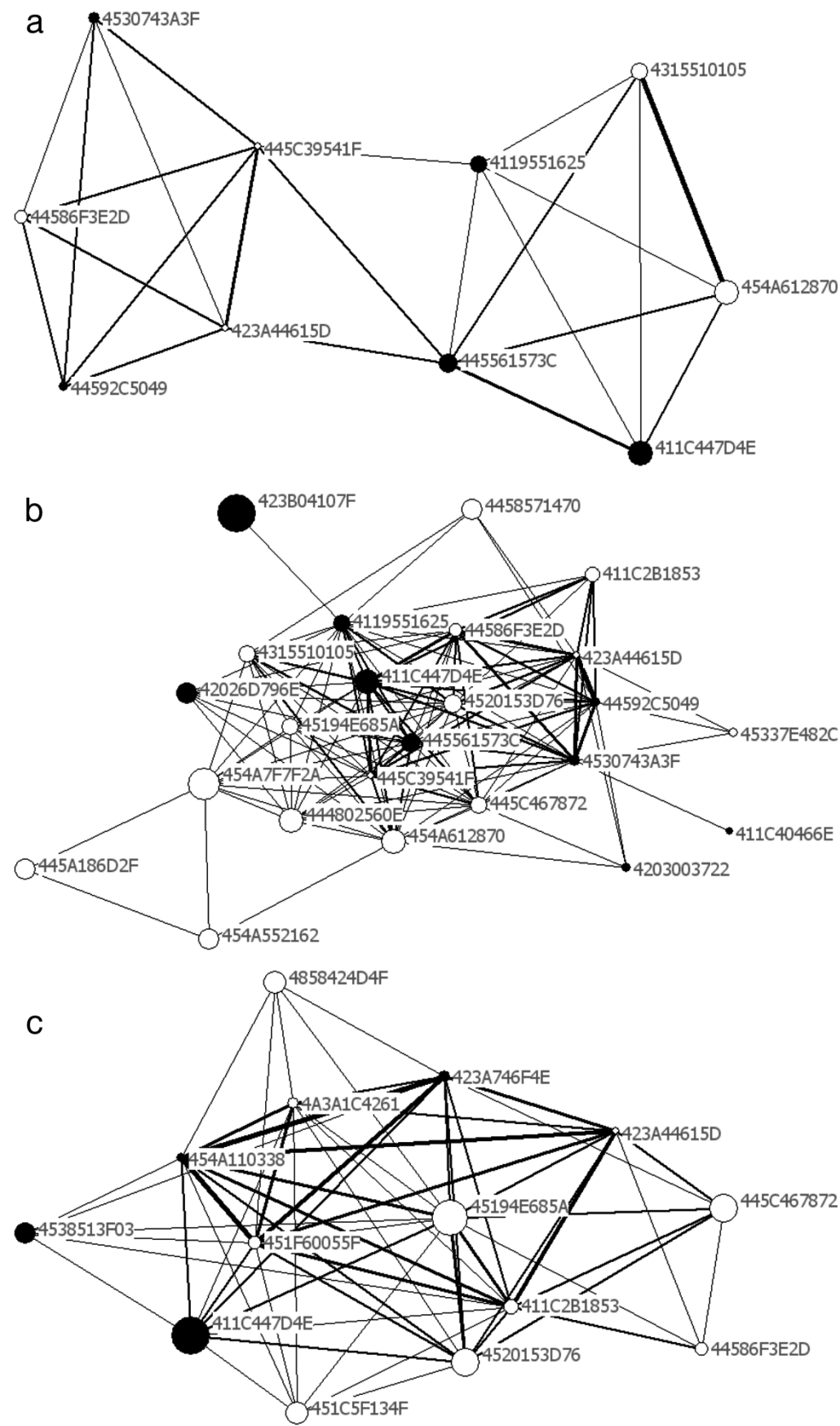

Fig. 3. Negaprion brevirostris. Visual representations of juvenile lemon shark social networks, for all group sizes. (a) July 14, 2006 (daily snapshot), (b) May to Dec 2006, (c) May to Dec 2007. Larger node size signifies larger shark body length. Thicker line edges between individuals signifies a higher number of groups that they were observed to interact in together. We only included groups that were at least 10 min apart (see 'Materials and methods' for details). Female $=$ filled nodes, male $=$ unfilled nodes

large immature lemon sharks were detected closer to shore at high tide versus low tide, indicating that predation pressure increased over the high tide phase of the tidal cycle (Guttridge 2009). Active hunting of small teleost fishes by juveniles was observed briefly on 4 occasions and only once was an actual feeding event observed in the study area (Guttridge 2009). Previously, groups of juvenile lemon sharks have been observed to corral small bait fish into shallow water (Morrissey \& Gruber 1993, Guttridge 2009); however, this behaviour was never observed during the present study.

For sharks, this investigation provides evidence for how assortative interactions based on body length both influence and structure a social network in the wild. But what mechanisms could produce such preferences for sizematched conspecifics? For bony fishes, it is thought that both passive and active mechanisms play a role in the formation of size-sorted groups (Croft et al. 2005). Juvenile lemon sharks aged 2 to $3 \mathrm{yr}$ showed active preferences for sizematched conspecifics when tested in captivity (Guttridge et al. 2009a). Teleost fishes tested in the laboratory also demonstrated this type of preference when deciding to join a group (Lachlan et al. 1998, Krause et al. 2000). However, the phenotypic assortment of social groups may also be dependent on size-specific habitat use (Croft et al. 2003) as well as swimming speeds (Krause et al. 2005). For the juvenile lemon sharks observed in the present study, assessment of their daily use of the aggregation site was determined in a parallel study (Guttridge 2009). It was hypothesised that the site served as a refuge over the high tide to avoid predation by larger conspecific sharks. Smaller sharks (aged 0 to $1 \mathrm{yr}$ ) visited the area more often, spent more time in the area and left on average later than larger lemon sharks (aged 2 to 4 yr) (Guttridge 2009). These differences could have provided the passive mechanism required to generate the betweengroup assortedness by body length found in the present study. Group joining decisions are complex and it is important to remember that other factors such as parasite load, behavioural phenotype and familiarity might also mediate these grouping decisions, as indicated in other animals (Krause \& Ruxton 2002, Croft et al. 2009). 
Table. 3. Negaprion brevirostris. Summary of results of leadership frequency square sum (LFSS) and the sum of individuals in a group that were smaller than the leader (SLS). See Table 2 for further explanations

\begin{tabular}{|lcccccc|}
\hline \multirow{2}{*}{ Analysis } & Time period & No. & Observed & Min/max scores & p-value \\
& & groups & score & & & \\
\hline \multirow{2}{*}{ LFSS } & May-Dec 06 & 668 & 49200 & 33932 & 44096 & 0.0000 \\
& Jan-May 07 & 164 & 5640 & 3694 & 6808 & 0.0149 \\
& May-Dec 07 & 472 & 25746 & 22348 & 27824 & 0.0418 \\
& Jan-May 08 & 220 & 9566 & 4958 & 7452 & 0.0000 \\
SLS & May-Dec 06 & 668 & 725 & 379 & 552 & 0.0000 \\
& Jan-May 07 & 164 & 198 & 69 & 153 & 0.0000 \\
& May-Dec 07 & 472 & 444 & 254 & 384 & 0.0000 \\
& Jan-May 08 & 220 & 257 & 120 & 221 & 0.0000 \\
\hline
\end{tabular}

We found no evidence for sex assortment in groups of socially interacting juvenile lemon sharks. In the lemon shark nurseries of Bimini, sex-based differences have not been detected for either habitat selection or prey preferences (Gruber et al. 1988, Morrissey \& Gruber 1993, Newman 2003, Franks 2007). As previously mentioned, shark social groups and aggregations composed of same sex individuals have been documented for numerous species (Economakis \& Lobel 1998, Wearmouth \& Sims 2008). Blue sharks Prionace glauca and scalloped hammerheads Sphyrna lewini exhibit sexually segregated schooling even in their early stages of life (Klimley 1987, Litvinov 2006). In these 2 studies, it was hypothesised that differences in prey preferences contributed to the observed sexual segregation. It would be useful for fisheries management to determine at what size or maturation this social change occurs and why some species show segregation at different life stages.

We also searched for associative patterns based on genetic relatedness and obtained mixed results. In 2006, related sharks significantly associated with each other, whereas in 2007 and 2008, no such patterns were detected. One possible explanation for these mixed results might be that the number of related sharks using the area was reduced over time due to natural mortality or possible emigration away from the site (DiBattista et al. 2008, Chapman et al. 2009). The mean number of observed relatives per individual was 2.2 in time period (1), 1.5 in (2), and further reduced to 0.74 in (3), supporting this hypothesis. Another potentially important factor is that our sample size was biggest for time period (1) and therefore provided the greatest statistical power to detect kin assortedness. Evidence for kin-structured free-ranging fish shoals has been obtained for a few species (Ward \& Hart 2003, Piyapong et al. 2010). Migratory charr Salvelinus fontinalis were found to have kin-structured subgroups with associations predicted to last for up to several years (Fraser et al. 2005). Several other studies have demonstrated that fish are capable of kin recognition (Olsen 1989, Gerlach \& Lysiak 2006). The mechanisms involved in such recognition vary depending on the ecology and sociality of the species involved (Sherman et al. 1997). Teleost fish can recognise kin based on familiarity and prior association, learning a common phenotype during early development (e.g. phenotype matching) (Ward \& Hart 2003). Teleosts can also use mechanisms independent of learning, where the phenotypic marker and recognition of that marker both have a genetic basis (Sherman et al. 1997, Gerlach \& Lysiak 2006). However, whether sharks are capable of such discrimination is presently unknown and until such information is available, it is difficult to interpret our results. Binary-choice experiments conducted on captive lemon sharks in parallel with genetics studies and wild observations will be required to explore this question further.

In the present study, pairs of free-ranging juvenile lemon sharks were more frequently led by some individuals than others and these individuals were often the largest in the pair. Leadership has been infrequently documented for captive sharks (Allee \& Dickinson 1954, Myrberg \& Gruber 1974, Brown 2004) and in all of these studies a hierarchy existed, with larger individuals taking up lead positions in groups of conspecifics. A series of binary choice experiments conducted with juvenile lemon sharks at the study site also found similar results, with smaller individuals (aged 0 to $1 \mathrm{yr}$ ) spending more time near a compartment with larger (aged 2 to 3 yr) sharks than size-matched conspecifics (Guttridge et al. 2009a). We hypothesise that smaller sharks are willing to follow larger (older) individuals because the latter have accumulated more information about the habitat, predators and local prey (Guttridge et al. 2009b). Associating with these larger individuals could facilitate the transfer of this information. In addition, it is important to note that it is unknown when a conspecific changes from being a social partner to a predator. Further behavioural trials are required in order to identify the factors affecting this change. For teleost fishes, behavioural phenotypes, such as bold versus shy, have been shown to mediate social interactions and leadership tendencies (Pike et al. 2008, Harcourt et al. 2009). Bold sticklebacks Gasterosteus aculeatus and guppies were observed to form fewer associations that were also on average weaker than those formed by shy individuals (Pike et al. 2008, Croft et al. 2009). For sharks, variation in individual behaviour and how it relates to habitat use and the formation of aggregations remains un- 
explored but could be an interesting topic for further research.

In conclusion, we have shown that juvenile lemon sharks form social groups that are non-random in their structure with individuals assorting by size, but not sex, and showing a preference to associate with relatives, in at least 1 yr of our study. Although we investigated the social structure of only 1 small population of juvenile lemon sharks, our results clearly illustrate that associative patterns occur even in young (aged 0 to 4 yr) sharks. These might confer important behavioural advantages that potentially enhance fitness, such as improved predator detection and avoidance.

Acknowledgements. T.L.G. was supported by a Leverhulme study abroad studentship. We thank the volunteers and staff at the Bimini Biological Field Station for their contribution. The study was also financially supported by grants from the Bimini Biological Field Station, The Hoover Foundation, Drs. T. and T. Fujino, The US National Science Foundation (NSFOCE 97-12793), NERC (NE/D011035/1) and Department of Education, State of Florida (FLORIDA 8749703000001). We also thank J. Uphill and D. James for assisting with data processing and analysis. This research was carried out under a permit from the Department of Fisheries of the Commonwealth of the Bahamas.

\section{LITERATURE CITED}

Allee WC, Dickinson JC (1954) Dominance and subordination in the smooth dogfish Mustelus canis (Mitchill). Physiol Zool 27:356-364

Brown L (2004) Daily patterns and activity periods in juvenile lemon sharks, Negaprion brevirostris. MSc thesis, Manchester Metropolitan University, Manchester

Chapman DD, Babcock EA, Gruber SH, Di Battista J and others (2009) Long-term natal site-fidelity by immature lemon sharks (Negaprion brevirostris) at a subtropical island. Mol Ecol 18:3500-3507

> Croft DP, Arrowsmith BJ, Bielby J, Skinner K and others (2003) Mechanisms underlying shoal composition in the Trinidadian guppy, Poecilia reticulata. Oikos 100:429-438

> Croft DP, Krause J, James R (2004) Social networks in the guppy (Poecilia reticulata). Proc R Soc Lond B 271: S516-S519

Croft DP, James R, Ward AJW, Botham MS, Krause J, Mawsdley D (2005) Assortative interactions and social networks in fish. Oecologia 143:211-219

Croft DP, James R, Thomas POR, Hathaway C, Mawsdley D, Laland KN, Krause J (2006) Social structure and co-operative interactions in a wild population of guppies (Poecilia reticulata). Behav Ecol Sociobiol 59:644-650

Croft DP, James R, Krause J (2008) Exploring animal social networks. Princeton University Press, Princeton, NJ

Croft DP, Krause J, Darden SK, Ramnarine IW, James R (2009) Behavioural trait assortment in a social network: patterns and implications. Behav Ecol Sociobiol 63:1495-1503

DiBattista JD, Feldheim KA, Gruber SH, Hendry AP (2008) Are indirect genetic benefits associated with polyandry? Testing predictions in a natural population of lemon sharks. Mol Ecol 17:783-795

Dudgeon CL, Noad MJ, Lanyon JM (2008) Abundance and demography of a seasonal aggregation of zebra sharks Stegostoma fasciatum. Mar Ecol Prog Ser 368:269-281

Economakis AE, Lobel PS (1998) Aggregation behavior of the grey reef shark, Carcharhinus amblyrhychos, at Johnston Atoll, Central Pacific Ocean. Environ Biol Fishes 51: 129-139

Feldheim KA, Gruber SH, Ashley MV (2002) The breeding biology of lemon sharks at a tropical nursery. Proc Biol Sci 269:1655-1661

Fewell JH (2003) Social insect networks. Science 301: $1867-1870$

Franks BR (2007) The spatial ecology and resource selection of juvenile lemon sharks Negaprion brevirostris in their primary nursery areas. PhD thesis, Drexel University, Philadelphia, PA

> Fraser DJ, Duchesne P, Bernatchez L (2005) Migratory charr schools exhibit population and kin associations beyond juvenile stages. Mol Ecol 14:3133-3146

Garla RC, Garcia J, Veras LB (2009) Fernando de Noronha as an insular nursery area for lemon sharks, Negaprion brevirostris, and nurse sharks, Ginglymostoma cirratum, in the equatorial western Atlantic Ocean. Mar Biodivers Rec 2: $1-4$

Gerlach G, Lysiak N (2006) Kin recognition and inbreeding avoidance in zebra fish Danio rerio, is based on phenotypic matching. Anim Behav 71:1371-1377

Godfrey SS, Bull CM, James R, Murray K (2009) Network structure and parasite transmission in a group living lizard, the gidgee skink, Egernia stokesii. Behav Ecol Sociobiol 63:1045-1056

Goodnight KF, Queller DC (1999) Computer software for performing likelihood tests of pedigree relationship using genetic markers. Mol Ecol 8:1231-1234

Griffiths SW (2003) Learned recognition of conspecifics by fishes. Fish Fish 4:256-268

Gruber SH, Myrberg AA Jr (1977) Approaches to the study of the behavior of sharks. Am Zool 17:471-486

Gruber SH, Nelson DR, Morrissey JF (1988) Patterns of activity and space utilisation of lemon sharks, Negaprion brevirostris in a shallow Bahamian lagoon. Bull Mar Sci 43: $61-76$

Guttridge TL (2009) The social organisation and behaviour of the juvenile lemon shark (Negaprion brevirostris). $\mathrm{PhD}$ thesis, University of Leeds, Leeds

Guttridge TL, Gruber SH, Gledhill KS, Croft DP, Sims DW, Krause J (2009a) Social preferences of juvenile lemon sharks, Negaprion brevirostris. Anim Behav 78:543-548

Guttridge TL, Myrberg AA, Porcer IF, Sims DW, Krause J (2009b) The role of learning in shark behaviour. Fish Fish 10:450-469

Harcourt JL, Ang TZ, Sweetman G, Johnstone RA, Manica A (2009) Social feedback and the emergence of leaders and followers. Curr Biol 19:248-252

Heupel MR, Simpfendorfer CA (2005) Quantitative analysis of aggregation behavior in juvenile blacktip sharks. Mar Biol 147:1239-1249

> Jacoby DMP, Busawon DS, Sims DW (2010) Sex and social networking: the influence of male presence on social structure of female shark groups. Behav Ecol 21(4): 808-818

Kessel ST (2010) An investigation into the behaviour and population dynamics of the lemon shark (Negaprion brevirostris). PhD thesis, Cardiff University, Cardiff

Klimley AP (1983) Social organization of schools of the scalloped hammerhead shark, Sphyrna lewini. PhD thesis, Scripps Institution of Oceanography, University of California, San Diego, CA 
Klimley AP (1987) The determinants of sexual segregation in scalloped hammerheads, Sphyrna lewini. Environ Biol Fish 18:27-40

Krause J (1994) The influence of food competition and predation risk on size-assortative shoaling in juvenile chub Leuciscus cephalus. Ethology 96:105-116

Krause J, Ruxton GD (2002) Living in groups. Oxford Series in Ecology and Evolution, Oxford University Press, Oxford

Krause J, Butlin RK, Peuhkuri N, Pritchard VL (2000) The social organization of fish shoals: a test of the predictive power of laboratory experiments for the field. Biol Rev Camb Phil Soc 75:477-501

Krause J, Ward AJW, Jackson AL, Ruxton GD, James R, Currie $S$ (2005) The influence of differential swimming speeds on composition of multi-species fish shoals. J Fish Biol 67: 866-872

Krause J, Croft DP, James R (2007) Social network theory in the behavioural sciences: potential applications. Behav Ecol Sociobiol 62:15-27

Krause S, Mattner L, James R, Guttridge TL, Corcoran MJ, Gruber SH, Krause J (2008) Social network analysis and valid Markov chain Monte Carlo tests of null models. Behav Ecol Sociol 63:1089-1096

Lachlan RF, Crooks L, Laland KN (1998) Who follows whom? Shoaling preferences and social learning of foraging information in guppies. Anim Behav 56:181-190

Landeau L, Terborgh J (1986) Oddity and the 'confusion effect' in predation. Anim Behav 34:1372-1380

Litvinov FF (2006) On the role of dense aggregations of males and juveniles in the functional structure of the range of the blue shark Prionace glauca. J Ichthyol 46:613-624

Lusseau D (2003) The emergent properties of a dolphin social network. Proc Biol Sci 270:S186-S188

Morrissey JF, Gruber SH (1993) Home range of juvenile lemon sharks, Negaprion brevirostris. Copeia 1993:425-434

Mucientes GR, Queiroz N, Sousa L, Tarroso P, Sims DW (2009) Sexual segregation of pelagic sharks and the potential threat from fisheries. Biol Lett 5:156-159

Myrberg AA Jr, Gruber SH (1974) Behaviour of the bonnethead shark, Sphyrna tiburo. Copeia 358-374

Newman SP (2003) Spatial and temporal variation in diet and prey preference of nursery bound juvenile lemon sharks, Negaprion brevirostris, at Bimini, Bahamas. PhD thesis, University of Plymouth, Plymouth
Olsen KH (1989) Sibling recognition in juvenile arctic charr, Salvelinus alpinus (L.). J Fish Biol 34:571-581

Parsons KM, Durban JW, Claridge DE, Balcomb KC, Noble LR, Thompson PM (2003) Kinship as a basis for alliance formation between male bottlenose dolphins, Tursiops truncatus, in the Bahamas. Anim Behav 66:185-194

Peuhkuri N, Ranta E, Seppa P (1997) Size-assortative schooling in free-ranging sticklebacks. Ethology 103:318-324

Pike TW, Samanta M, Lindstrom J, Royle NJ (2008) Behavioural phenotype affects social interactions in an animal network. Proc R Soc Lond Ser B 275:2515-2520

Pitcher TJ, Parrish JK (1993) Functions of shoaling behaviour in teleosts. In: Pitcher TJ (ed) Behaviour of teleosts. Chapman \& Hall, London, p 363-439

Piyapong C, Butlin RK, Faria JJ, Wang J, Krause J (2010) Kin assortment in juvenile shoals in wild guppy populations. Heredity doi:10.1038/hdy.2010.115

Queller DC, Goodnight KF (1989) Estimating relatedness using genetic markers. Evolution 43:258-275

Reyier EA, Adams DH, Lowlers RH (2008) First evidence of a high density nursery ground for the lemon shark, Negaprion brevirostris, near Cape Canaveral, Florida. For Sci 71:134-148

Ruckstuhl KE, Neuhaus P (2005) Sexual segregation in vertebrates. Cambridge University Press, Cambridge

Sherman PW, Reeve HK, Pfennig DW (1997) Recognition systems. In: Krebs JR, Davies NB (eds) Behavioural ecology: an evolutionary approach. Blackwell Scientific, Oxford, p 69-96

Svensson PA, Barber I, Forsgren E (2000) Shoaling behaviour of the two-spotted goby. J Fish Biol 56:1477-1487

Ward AJW, Hart PJB (2003) The effects of kin and familiarity on interactions between fish. Fish Fish 4:348-358

Ward AJW, Webster MM, Magurran AE, Currie S, Krause J (2009) Species and population differences in social recognition between fishes: a role for ecology? Behav Ecol 20: 511-516

- Wearmouth VJ, Sims DW (2008) Sexual segregation in marine fish, reptiles, birds and mammals: Behaviour patterns, mechanisms and conservation implications. Adv Mar Biol $54: 107-170$

Whitehead H (2008) Analyzing animal societies: quantitative methods for vertebrate social analysis. University of Chicago Press, Chicago, IL

Appendix 1. Negaprion brevirostris. Summary of results at different group sizes of association strength square sum (ASSS) and size assortment based on the sum of standard deviations in all groups. See Table 2 for further explanations

\begin{tabular}{|c|c|c|c|c|c|c|c|}
\hline Group size & Time period & Time dist (min) & No. groups & Observed score & \multicolumn{2}{|c|}{ Min/max scores } & $\mathrm{p}$-value \\
\hline \multicolumn{8}{|l|}{ ASSS } \\
\hline 2 & May-Dec 06 & 10 & 265 & 2861 & 1479 & 2861 & 0.00000 \\
\hline 2 & May-Dec 06 & 60 & 87 & 261 & 163 & 321 & 0.00342 \\
\hline 2 & May-Dec 07 & 10 & 196 & 1956 & 1066 & 1956 & 0.00000 \\
\hline 2 & May-Dec 07 & 60 & 60 & 262 & 134 & 296 & 0.00018 \\
\hline$>2$ & May-Dec 06 & 10 & 184 & 17330 & 15724 & 17672 & 0.00245 \\
\hline$>2$ & May-Dec 06 & 60 & 64 & 1881 & 1631 & 2071 & 0.01460 \\
\hline$>2$ & May-Dec 07 & 10 & 144 & 20426 & 18214 & 20426 & 0.00000 \\
\hline$>2$ & May-Dec 07 & 60 & 44 & 1361 & 1125 & 1407 & 0.00015 \\
\hline$>3$ & May-Dec 06 & 10 & 93 & 10831 & 10073 & 11103 & 0.00617 \\
\hline$>3$ & May-Dec 06 & 60 & 44 & 1962 & 1770 & 2090 & 0.01523 \\
\hline$>3$ & May-Dec 07 & 10 & 84 & 15870 & 15314 & 16110 & 0.00736 \\
\hline$>3$ & May-Dec 07 & 60 & 28 & 1454 & 1396 & 1546 & 0.38863 \\
\hline
\end{tabular}


Appendix 1. (continued)

\begin{tabular}{|c|c|c|c|c|c|c|c|}
\hline Group size & Time period & Time dist (min) & No. groups & Observed score & \multicolumn{2}{|c|}{ Min/max scores } & $\mathrm{p}$-value \\
\hline \multicolumn{8}{|c|}{ Size assortment } \\
\hline 2 & May-Dec 06 & 10 & 265 & 1270 & 1270 & 1749 & 0.00001 \\
\hline 2 & May-Dec 06 & 60 & 87 & 436 & 405 & 626 & 0.00051 \\
\hline 2 & May-Dec 07 & 10 & 196 & 812 & 811 & 1441 & 0.00000 \\
\hline 2 & May-Dec 07 & 60 & 60 & 227 & 227 & 405 & 0.00000 \\
\hline$>2$ & May-Dec 06 & 10 & 184 & 1387 & 1387 & 1606 & 0.00001 \\
\hline$>2$ & May-Dec 06 & 60 & 64 & 438 & 438 & 550 & 0.00000 \\
\hline$>2$ & May-Dec 07 & 10 & 144 & 984 & 983 & 1141 & 0.00001 \\
\hline$>2$ & May-Dec 07 & 60 & 44 & 314 & 284 & 383 & 0.00207 \\
\hline$>3$ & May-Dec 06 & 10 & 93 & 785 & 785 & 867 & 0.00000 \\
\hline$>3$ & May-Dec 06 & 60 & 44 & 381 & 370 & 421 & 0.00041 \\
\hline$>3$ & May-Dec 07 & 10 & 84 & 582 & 572 & 622 & 0.00067 \\
\hline$>3$ & May-Dec 07 & 60 & 28 & 209 & 205 & 220 & 0.04595 \\
\hline
\end{tabular}

Appendix 2. Negaprion brevirostris. Additional time periods: association strength square sum (ASSS); size assortment based on the sum of standard deviations in all groups; sex assortment based on the sum of the maximum values of the number of males and females in all groups; and relatedness based on the number of related pairs of individuals in groups. See Table 2 for further explanations

\begin{tabular}{|c|c|c|c|c|c|c|c|}
\hline \multirow{2}{*}{$\begin{array}{l}\text { Analysis } \\
\text { ASSS }\end{array}$} & \multirow{2}{*}{$\begin{array}{l}\text { Time period } \\
\text { Jan-May } 07\end{array}$} & \multirow{2}{*}{$\begin{array}{c}\text { Time dist (min) } \\
10\end{array}$} & \multirow{2}{*}{$\begin{array}{c}\text { No. groups } \\
97\end{array}$} & \multirow{2}{*}{$\begin{array}{c}\text { Observed score } \\
6175\end{array}$} & \multicolumn{2}{|c|}{ Min/max scores } & \multirow{2}{*}{$\begin{array}{c}\mathrm{p} \text {-value } \\
0.0132\end{array}$} \\
\hline & & & & & 5625 & 6441 & \\
\hline & Jan-May 07 & 60 & 25 & 473 & 417 & 515 & 0.1235 \\
\hline & Jan-May 08 & 10 & 86 & 2383 & 1965 & 2713 & 0.0367 \\
\hline & Jan-May 08 & 60 & 21 & 171 & 109 & 207 & 0.0036 \\
\hline \multirow[t]{4}{*}{ Size } & Jan-May 07 & 10 & 97 & 608 & 572 & 675 & 0.0353 \\
\hline & Jan-May 07 & 60 & 25 & 162 & 143 & 186 & 0.1083 \\
\hline & Jan-May 08 & 10 & 86 & 608 & 579 & 802 & 0.0006 \\
\hline & Jan-May 08 & 60 & 21 & 148 & 106 & 198 & 0.1105 \\
\hline \multirow[t]{4}{*}{ Sex } & Jan-May 07 & 10 & 97 & 242 & 242 & 247 & 0.7882 \\
\hline & Jan-May 07 & 60 & 25 & 65 & 65 & 65 & 0.7144 \\
\hline & Jan-May 08 & 10 & 86 & 206 & 206 & 213 & 0.6565 \\
\hline & Jan-May 08 & 60 & 21 & 48 & 48 & 50 & 0.4249 \\
\hline \multirow[t]{2}{*}{ Kin } & Jan-May 07 & 10 & 97 & 50 & 44 & 61 & 0.8076 \\
\hline & Jan-May 07 & 60 & 25 & 11 & 9 & 16 & 0.8591 \\
\hline
\end{tabular}

Editorial responsibility: Hans Heinrich Janssen, Oldendorf/Luhe, Germany
Submitted: April 20, 2010; Accepted: November 11, 2010

Proofs received from author(s): January 31, 2011 